\title{
OPINIÃO DE UNIVERSITÁRIOS SOBRE O USO DO CONDOM E SUA INFLUÊNCIA NO EXERCÍCIO DA SEXUALIDADE
}

\author{
UNDERGRADUATE STUDENT'S OPINION CONCERNING THE CONDOM USE \\ AND ITS INFLUENCE ON SEXUALITY
}

Elucir Gir ${ }^{1}$, Geraldo Duarte ${ }^{2}$, Milton Jorge de Carvalho ${ }^{3}$

Docentes $^{1,2,3}$ dos Departamentos de: Enfermagem Geral e Especializada da Escola de Enfermagem; Ginecologia e Obstetrícia da Faculdade de Medicina ${ }^{2}$ de Ribeirão Preto da Universidade de São Paulo; e da Disciplina de: Ginecologia e Obstetrícia da Faculdade de Medicina do ABC, Santo André - São Paulo³.

CorRESPOndÊNCIA: Elucir Gir. Avenida Bandeirantes, 3900. (EERP-USP). CEP: 14040-902. Ribeirão Preto-SP . Fax (016) $633-3271$. Email : egir@usp.br

GIR E; DUARTE G \& CARVALHO MJ de. Opinião de universitários sobre o uso do condom e sua influência no exercício da sexualidade. Medicina, Ribeirão Preto, 30: 100-105, jan./mar. 1997.

RESUMO: Objetivando detectar a opinião de estudantes universitários sobre o uso de condom e sua influência no exercício da sexualidade, aplicou-se um questionário, com cinco questões, em 534 estudantes universitários, em Ribeirão Preto - SP (Curso de Enfermagem, Medicina, Psicologia, Farmácia-Bioquímica). Quanto aos resultados, destacam-se as freqüências modais, a saber: $216(40,5 \%)$ dos entrevistados referiram não saber se "o uso da camisinha é uma prática antinatural";467 (87,5\%) concordaram com a afirmativa "o uso da camisinha evita AIDS e outras DST". Para o item: "a camisinha deve ser usada apenas como método anticoncepcional", $408(76,4 \%)$ discordaram. Quanto à questão: "o uso da camisinha ofende o parceiro sexual", verificou-se que $328(61,4 \%)$ não sabiam opinar com segurança. No último item: "o uso da camisinha atrapalha no prazer sexual", verificou-se que $291(54,5 \%)$ não sabiam a resposta. Avaliando os resultados, nota-se que a crença dos mitos associados ao uso do condom, como fator que interfere no prazer sexual, ainda é grande. As crenças negativas atribuídas ao seu uso devem ser trabalhadas para não interferirem no exercício da sexualidade dos indivíduos $\mathrm{O}$ uso correto e sistemático do condom, na era da AIDS, deve ser incorporado ao comportamento das pessoas, uma vez que é comprovada sua eficácia como preventivo contra as DST.

UNITERMOS: Condom. Estudantes de Ciências da Saúde. Sexo.

\section{INTRODUÇÃO}

Com o advento da anticoncepção farmacológica e de terapêuticas eficazes contra as doenças sexualmente transmissíveis (DST), nota-se que a preocupação em evitar a gravidez e prevenir tais doenças vem sendo reduzida. Por outro lado, ocorreram profundas mudanças no comportamento sexual, e, hoje, a relação sexual dissociada de vínculos conjugais ou afetivos passou a fazer parte do coti- diano íntimo do ser humano. Acrescentam-se a essas mudanças, a liberação da mulher, o uso de estímulos eróticos em propagandas direcionadas à mídia e a multiplicidade de parceria sem, necessariamente, estar ligada à prostituição. Caracteriza-se, portanto, a revolução sexual ou era do "sexo pelo sexo", pela ampla permissividade, visando à obtenção do prazer sexual. Paralelamente a tais mudanças, observou-se que o uso do condom declinou drasticamente. 
No início dos anos 80, o uso do condom por homens cujas parceiras estavam em idade reprodutiva não ultrapassava 5\%. Nos países mais desenvolvidos, esse índice atingiu 13\%, e 3\% para os não-industrializados. No Japão, foi detectado um total de $45 \%$ de usuários, $40 \%$ na Finlândia; 39\% na Dinamarca, $33 \%$ em Singapura, $21 \%$ na Espanha e 14\% nos EUA. No Brasil, em 1991, evidenciou-se que, dentre 30000 mulheres estudadas, na faixa etária entre 15 e 54 anos, $70 \%$ faziam uso de algum método contraceptivo, dos quais apenas $1,8 \%$ mencionaram usar condom ${ }^{1}$. Outra publicação confirma o Japão como o país com maior número de usuários de condom, contrastando com a baixa frequiência do seu uso entre o povo africano ${ }^{2}$.

Enquanto protetor, o condom contribui para reduzir o risco de infecções adquiridas através da exposição do pênis à região cervical, vaginal, vulvar, anal, ressaltando-se que esta eficácia está diretamente associada ao uso correto e regular, bem como à qualidade do condom. Outrossim, vale enfatizar que as pesquisas visando analisar o uso correto de preservativos são feitas com base em relatos de usuários, o que determina um fator limitante.

A mínima porosidade (permeabilidade) do condom de látex evita a passagem de vírus transmitidos sexualmente, dentre eles o HIV-1, mesmo sob pressão hidrostática ${ }^{3,4}$. No que refere à eficácia específica sobre o HIV-1, a literatura mostra que há evidências significativas de que o condom, com qualidade comprovada, oferece efeito protetor contra esse vírus.

Segundo a ORGANIZAÇÃO MUNDIAL DA SAÚDE $(1990)^{5}$,os preservativos de látex são os recomendados como método de barreira, enquanto os condons feitos com intestino de carneiro são contra-indicados, por conterem pequenos poros que permitem a passagem do HIV-1. Segundo CATES (1988) ${ }^{6}$, essa permeabilidade permite, também, a passagem do vírus da Hepatite B. Além disso, oferecem proteção contra as bactérias causadoras da doença inflamatória pélvica,de vírus ligados ao câncer cervical (papilomavírus), contribuindo, assim, para o sexo seguro ${ }^{2}$.

A liberação sexual e liberdade de desejos, associadas ao avanço tecnológico da reprodução humana, possibilitaram o exercício da sexualidade sem se preocupar com reprodução, e de reproduzir-se independentemente de fazer sexo (inseminação artificial, fertilização "in vitro" e transferência de embriões). Tudo caminhava em ritmo de explosão sexual, até o surgimento da AIDS, nos anos 80, impondo medos e insegurança quanto à prática sexual, e, conseqüientemente, modificações no comportamento.

A história do condom é secular e sua trajetória e uso recebem diferentes conotações, com influência de diversos aspectos sócio-culturais. O preconceito atribuído ao uso do preservativo é, sobretudo, uma variável determinante para o exercício sexual inseguro. A incorporação e introjeção de opiniões, sem dúvida, reflete no comportamento e, portanto, nesse sentido, o exercício da sexualidade pode ser influenciado, de maneira negativa, por crenças sem fundamentos.

Assim, decidiu-se realizar, com o objetivo de detectar a opinião de estudantes universitários da área da Saúde, esta investigação sobre o uso de preservativo e sua influência no exercício da sexualidade.

\section{MATERIAL E MÉTODOS}

De 1111 alunos regularmente matriculados nos cursos de graduação em Enfermagem, Medicina, Psicologia e Farmácia-Bioquímica, da Universidade de São Paulo - Campus de Ribeirão Preto, um total de $534(48,1 \%)$ constituíram a amostra deste trabalho. Eram $371(69,5 \%)$ do sexo feminino e 163 (30,5\%) do sexo masculino, com idade variando entre 18 e 30 anos.

Para a coleta de dados, utilizou-se, como instrumento, um questionário especificamente elaborado para esta investigação, composto por cinco itens, que apresentavam alternativas para as respostas em três pontos, ou sejam:

1. O uso da camisinha é uma prática antinatural.

2. O uso da camisinha evita AIDS e outras Doenças Sexualmente Transmissíveis.

3. A camisinha deve ser usada apenas como método anticoncepcional.

4. O uso da camisinha ofende o(a) parceiro (a) sexual. 5. O uso da camisinha atrapalha no prazer sexual.

Como alternativas para as respostas, constavam:

a. CONCORDO b. NÃO SEI c. DISCORDO

O instrumento foi submetido à validação de conteúdo feita por profissionais com experiência em psicometria, que analisaram se os itens estavam claros, concisos e coerentes para o cumprimento dos objetivos. Após as sugestões serem analisadas e acatadas, realizou-se o estudo piloto, cujos resultados evidenciaram que o instrumento era adequado e pertinente aos objetivos propostos. 
Sobre os procedimentos, ressalta-se que o questionário foi aplicado nas salas de aula de cada grupo, no início ou término de aula, mediante prévia permissão da diretoria e professores das unidades. A aplicação foi coletiva e, após distribuir o instrumento, explicava-se o objetivo da pesquisa, esclarecia-se sobre o anonimato das respostas, bem como facultava aos alunos a liberdade de aceitarem ou não responderem o questionário. Foram incluídos, portanto, somente os que aquiesceram em participar e que responderam o questionário de forma completa. Destaca-se que apenas 11 sujeitos foram excluídos, por não terem respondido as cinco questões, e 4 recusaram-se a participar.

\section{RESULTADOS E DISCUSSÃO}

Os resultados obtidos através do questionário respondido por 534 estudantes estão apresentados na Tabela I, onde se tem os valores modais, em negrito.

Tabela I - Distribuição das respostas referentes aos itens do questionário para avaliar a opinião de estudantes universitários sobre o uso do condom. Ribeirão Preto - SP, 1994

\begin{tabular}{|c|c|c|c|c|c|c|c|c|}
\hline \multirow[t]{2}{*}{ ITEM } & \multicolumn{2}{|c|}{ CONCORDO } & \multicolumn{2}{|c|}{ NÃO SEl } & \multicolumn{2}{|c|}{ DISCORDO } & \multicolumn{2}{|c|}{ TOTAL } \\
\hline & $\mathrm{n}^{0}$ & $\%$ & $\mathrm{n}^{\circ}$ & $\%$ & $\mathrm{n}^{0}$ & $\%$ & $\mathrm{n}^{0}$ & $\%$ \\
\hline 1. O uso da camisinha é uma prática antinatural. & 109 & 20,4 & 216 & 40,5 & 209 & 39,1 & 534 & 100 \\
\hline 2. O uso da camisinha evita AIDS e outras DST. & 467 & 87,5 & 54 & 10,1 & 13 & 2,4 & 534 & 100 \\
\hline $\begin{array}{l}\text { 3. A camisinha deve ser usada apenas como método } \\
\text { anticoncepcional. }\end{array}$ & 71 & 13,3 & 55 & 10.3 & 408 & 76,4 & 534 & 100 \\
\hline 4. O uso da camisinha ofende o(a) parceiro(a) sexual. & 48 & 9,0 & 328 & 61,4 & 158 & 29,6 & 534 & 100 \\
\hline 5. O uso da camisinha atrapalha o prazer sexual. & 109 & 20,4 & 291 & 54,5 & 134 & 25,1 & 534 & 100 \\
\hline
\end{tabular}

Em relação à assertiva: "O uso da camisinha é uma prática antinatural", $216(40,5 \%)$ estudantes referiram não saber a resposta; $109(20,4 \%)$ mencionaram concordar que se trata de uma prática antinatural e $209(39,1 \%)$ discordaram. A alternativa ideal seria "discordo", no entanto, o valor modal recaiu sobre a alternativa "não sei", embora a diferença entre ambas equivalha a apenas $1,3 \%$. Por outro lado, somando-se as respostas "concordo" e "não sei", observa-se que $325(60,9 \%)$ dos $534(100 \%)$ entrevistados atribuíram respostas contrárias ao desejado.

Sobre a questão "O uso da camisinha evita AIDS e outras DST", a maioria, 467 (87,5\%) dos acadêmicos, referiram concordar com esta alternativa, evidenciando noção correta sobre uma das finalidades do condom. Um total de $54(10,1 \%)$ mencionaram não saber a resposta e $13(2,4 \%)$ discordaram. Obteve-se, assim, um resultado altamente positivo para esse item.

Quanto à afirmativa: "A camisinha deve ser usada apenas como método anticoncepcional", 408 (76,4\%) dos universitários discordaram da afirmação, enquanto $126(23,6 \%)$ concordaram ou não sabiam a resposta. Tal resultado também pode ser considerado positivo, pois demonstra que a maioria dos entrevistados reconhecem a finalidade não-exclusiva do condom, isto é, apenas como barreira contraceptiva. Associando o resultado para a assertiva 2, pode-se presumir que, pelo menos, $76,4 \%$ dos estudantes são cientes da finalidade múltipla do preservativo, ou seja, como protetor contra DST e como contraceptivo.

Analisando os dados disponíveis na literatura, depreende-se que, historicamente, a finalidade inicial do condom foi de prevenção contra as DST (século $\mathrm{XVI}$ ), e, posteriormente, passou a ter finalidade contraceptiva (século XVIII) ${ }^{7}$.

Ressalta-se que o fato de estarem cientes das finalidades, não significa que o condom seja empregado no cotidiano sexual dos alunos avaliados, pois, conforme refere POMPIDOU $(1988)^{8}$, estar informado não significa necessariamente conhecer, estar ciente não significa necessariamente tomar medidas, decidir não significa necessariamente fazer.

Em uma investigação sobre o conhecimento e uso de condons entre estudantes universitários, bancários, operários da indústria e construção civil, BERQUÓ \& SOUZA $(1991)^{1}$ entrevistaram 300 homens com idade entre 18 a 30 anos. O condom foi o método masculino mais citado como anticoncepcional. Para evitar as DST, foi mencionado, entretanto, com freqüência menor do que no caso da anticoncepção. Os entrevistados tinham conhecimento de que o condom apresenta duplo propósito, ou seja, contraceptivo e 
profilático contra as DST. Quanto à eficácia, a maioria o considerou mais eficaz para prevenção de DST do que para evitar gravidez, exceção feita aos industriários pesquisados, que julgaram o condom igualmente eficaz para ambas as finalidades. Um total de $80 \%$ dos entrevistados referiram já ter usado condom, e, com a finalidade principal de contracepção, para os bancários e universitários, e, como preventivo de DST, para os operários. Dentre os motivos apontados para a não-utilização do condom destacaram-se o "tira prazer", falta de hábito, custo elevado, vergonha em usá-lo.

Sobre a questão: "O uso da camisisinha ofende o (a) parceiro(a) sexual, $328(61,4 \%)$ referiram não saber a resposta, $48(9,0 \%)$ concordaram e 158 $(29,6 \%)$ discordaram.

De forma similar, para a afirmativa: "O uso da camisinha atrapalha o prazer sexual", obteve-se o valor modal na alternativa "não sei", onde $291(54,5 \%)$ alunos manifestaram-se dessa forma; $134(25,1 \%)$ referiram discordar e $109(20,4 \%)$ não saber.

Percebe-se que, para as questões 1,4 e 5, o valor modal contemplou a alternativa "não sei", denotando que a maioria dos entrevistados apresentam opinião contrária à desejada. O ideal seria a resposta "discordo", indicando que as pessoas não consideram como verdades essas crenças populares. Na literatura, essas crenças são consideradas como fatores que interferem de maneira negativa no desempenho sexual e, somadas a numerosas outras, figuram como elementos que fortalecem a relutância de muitas pessoas para não incorporarem o condom em seu comportamento sexual, ou fazê-lo de maneira incorreta ou assistemática.

Dentre as razões atribuídas ao não-uso ou uso irregular, vários autores ${ }^{3,9,10}$ destacam: redução da sensibilidade masculina e feminina durante o coito; não aceitação pelo parceiro; idéias errôneas sobre a eficácia e efeitos colaterais; embaraço associado à compra do preservativo; ausência do conhecimento/ interesse sobre o uso.Outras razões são citadas, tais como: a inconveniência do método devido à necessidade de usar o condom em cada ato sexual, colocá-lo no decurso do encontro sexual e tê-lo disponível no momento, a má reputação dos condons devido à sua tradicional associação com DST e prostituição ${ }^{2}$.

A interferência no ato sexual, a não-naturalidade do uso, insatisfação, desconforto, irritação, desconfiança, esquecimento, dentre outras, foram razões detectadas por DARROW (1974) $)^{11}$, em seu estudo realizado sobre o condom, compilando as opiniões de 2325 americanos.

Em 1974, HART ${ }^{12}$ alega que os motivos determinantes que levaram os participantes de suas pesquisas (pacientes de uma clínica de DST) a não fazerem uso regular de condom foram diminuição do prazer, percepção errônea sobre o risco de infecção e não-disponibilidade do preservativo na hora da relação.

Em trabalho desenvolvido por HINGSON et al. $(1990)^{13}$, entre adolescentes de Massachussets, revelou-se que os motivos que conduzem ao não-uso ou uso assistemático de condom são: crenças sobre a redução do prazer ou ainda, rotineiramente, eles não carregarem consigo condons.

Mensurando as atitudes sobre o condom, HART $(1975)^{14}$ comparou três estudos, que datam de 1944 a 1974, e evidenciou que as principais razões para o fracasso do uso do condom e as razões mais comuns encontradas foram: a não-disponibilidade, o fato de a infecção ser considerada improvável, prejuízo no prazer e uso de álcool mediando decisões sobre o uso dos preservativos.

LIBBUS (1995) $)^{15}$, estudando as crenças de 58 mulheres americanas com relação à aquisição e uso do condom, concluiu que essas mulheres referem o acesso e a eficácia enquanto preventivo de gravidez e DST como pontos vantajosos para a aquisição e uso do condom. Como desvantagens e aspectos que contribuem para impedir esse uso destacam: embaraço, objeções do parceiro masculino, efeito na espontaneidade. Apesar de estarem cientes dos benefícios, as crenças negativas determinam a decisão de reduzir a probabilidade do uso consistente.

É perfeitamente evidente que a soma de fatores negativos e estereotipados, atribuídos ao uso do condom, contribuam fortemente para o não-uso, uso irregular ou inadequado. Embora a grande maioria dos estudos realizados tenham avaliado principalmente indivíduos não-brasileiros, parece que as limitações são praticamente homogêneas, independentemente da localização geográfica.

O presente estudo, embora não permitindo generalizações, oferece idéias das constantes verbalizações ouvidas por brasileiros. Na literatura consultada, não foi encontrado nenhum trabalho que possibilitasse comparação com os dados aqui obtidos. As investigações evidenciam crenças que determinam o uso assistemático ou desuso do condom, não tendo sido encontradas pesquisas que comprovassem se o condom ofende o parceiro e se realmente atrapalha o prazer sexual.

Estatísticas globais precisas sobre o uso do condom como preventivo contra DST inexistem. A soma de estudos isolados permite uma noção sobre a situação, sugerindo que este uso é infreqüente, assistemático e não atinge as cifras desejáveis como deveria, uma vez que o uso correto do condom constitui alternativa preventiva 
e efetiva contra as DST. Resultados de vários trabalhos, in vivo ou in vitro, indicam e reafirmam a eficácia do condom como método de barreira contra agentes causadores de DST ${ }^{2,16 / 22}$.

Portanto, às vésperas do século XXI, a infecção do HIV-1 disseminando-se progressiva e predominantemente por via sexual, é imperiosa a necessidade da sensibilização dos indivíduos quanto à necessidade de desmistificarem o uso do condom e considerá-lo como componente indispensável na prática sexual do seu dia-a-dia. Os sujeitos aqui estudados, como futuros profissionais da Saúde e, portanto, prestadores de assistência, vivenciam o problema sob dois prismas: o pessoal e o profissional. Se um indivíduo carrega consigo preconceitos, ele pode transmiti-los, o que é indesejável. Assim, é fundamental trabalhar os estudantes no sentido de sensibilizá-los quanto à adoção do condom na sua vida sexual, sem conflitos, e o repasse deste comportamento aos seus clientes.

\section{CONSIDERAÇÕES FINAIS}

Historicamente, o uso de condons esteve associado à prostituição, promiscuidade e relações extra-conjugais. Soma-se a essa má reputação a percepção, ainda atual, tanto pelo homem como pela mulher, de que o condom é um determinante que prejudica o prazer sexual, podendo acarretar difícil acordo interpessoal, resultando em embaraço e desconfiança, além de numerosas outras crenças que norteiam sua subutilização.

Estudos comprovam sua efetividade tanto como contraceptivo como profilático contra DST. No en- tanto, estamos vivendo uma fase bastante conflitante em termos de comportamento sexual. Nessa era em que a AIDS se encontra em franca disseminação e a transmissão sexual constitui-se na mais importante via de disseminação do HIV no mundo, a relação sexual com preservativo é considerada uma das medidas seguras, desde que o seu uso seja correto e sistemático.

O conflito se estabelece justamente na indicação do condom, pois, se hoje é fundamental, por outro lado, os indivíduos não o priorizam em todos os eventos sexuais. Relegá-lo a plano secundário, usando-o de maneira incorreta e/ou assistemática, tem, como fio condutor, as crenças negativas e preconceitos atribuídos ao condom. Nessa investigação, ficaram evidentes que, mesmo entre universitários, essas crenças se configuram como verdades. Sendo assim, o exercício da sexualidade, sob influência dos preconceitos, fica prejudicado e pode, então, ocorrer interferência na qualidade do ato sexual.

A educação sexual sistematizada deve ser priorizada no nosso cotidiano, pois, desta forma, as crenças negativas atribuídas ao uso do condom devem ser trabalhadas e, portanto, poderão ser desmistificadas. Assim, as pessoas poderão exercer a sua sexualidade de maneira gratificante e segura.

Pretende-se, como profissional da área da Saúde, envidar esforços para que, a nível de Ensino do Terceiro Grau, este assunto seja introduzido nos currículos. Logicamente, essa não é a única medida necessária para minimizar a questão, mas, sem dúvida, é uma das importantes estratégias. Outras medidas devem ser iniciadas e somadas, em fase de escolaridade anterior.

GIR E; DUARTE G \& CARVALHO MJ de. Undergraduate student's opinion concerning the condom use and its influence on sexuality. Medicina, Ribeirão Preto, 30: 100-105, jan./march 1997.

ABSTRACT: In order to detect the undergraduate student's opinion about the condom use and its influence on sexuality, a five-question questionnaire was applied in 534 undergraduate students from Ribeirão Preto (Nursing, Medical, Psychology, Pharmacy-Biochemistry). Concerning the results, the most frequent answers are emphasized. A total of $216(40,5 \%)$ of the interviewed people referred that they did not know if "the use of condom is an anti-natural procedure", 467 $(87,5 \%)$ agreed with the sentence "the condom use avoid AIDS and other STD". In question 3, 408 $(76,4 \%)$ disagreed with "condom must be worn only as a contraceptive method", In the questions "condom use offend the sexual partner" and "the condom uses interferes in sexual pleasure", 328 $(61,4 \%)$ and 291 (54,5\%) did not know the answer respectively. By evaluating these results, we observed that the belief on myths associated to condom use, as a factor that interfere on sexual pleasure is relevant. The negative beliefs attributed to its use must be worked in order to not interfere on human sexuality. The correct and sistematic use of condom, in the AIDS era, must be incorporated in people's bahavior, since its efficacy is certain as a STD preventive method.

UNITERMS: Condoms. Students, Health Occupations. Sex. 


\section{REFERÊNCIAS BIBLIOGRÁFICAS}

1 - BERQUÓ E \& SOUZA MR. Conhecimento e uso do condom: anticoncepção e prevenção de doenças sexualmente transmissíveis. UNICAMP, Campinas, 1991. /texto NEPO - Núcleo de Estudos da População, n.20/.

2 - SHERRIS JD; LEWISON D \& FOX G. Atualização sobre condons: produtos, proteção e promoção. Population Reports n.6, p.H.1- H.40, 1983. /Série H/.

3 - HEPWORTH J \& SHERNOFF M. Strategies for AIDS education and prevention. In: MACKLIN ED. AIDS and families. Harrington Park Press, New York, cap.2, p.39-80, 1989.

4 - GOLDSMITH MF. Sex in the age of AIDS calls for common sense and "condom sense". JAMA 257: 2261-2263, 2266, 1987.

5 - ORGANIZAÇÃO MUNDIAL DA SAÚDE. AIDS Série 3: prevenção contra a transmissão sexual do vírus da imunodeficiência humana. Ed. Santos, São Paulo, 1990.

6 - CATES W. Las enfermedades transmitidas sexualmente y la selección de anticonceptivos. Outlook p.2-7, dic., 1988.

7 - GIR E; DUARTE G \& CARVALHO MJ. Condom: sexo e sexualidade. MEDICINA, Ribeirão Preto 29: 309-314, 1996.

8 - POMPIDOU A. National AIDS information programme in France. In: WORLD HEALTH ORGANIZATION. AIDS: prevention and control. Pergamon Press, Geneva, p.28-31, 1988.

9 - FISCHL MA. Prevenção da transmissão da AIDS durante a relação sexual. In: DE VITA V; HELLMAN S; ROSEMBERG S. A. AIDS: etiologia, diagnóstico, tratamento e prevenção. Trad. de Paulo Dias da Costa. 2. ed., Revinter, Rio de Janeiro, 1991, cap.22, p.337-383, 1991.

10 - BERTRAND JT et al. AIDS - related knowledge, sexual behavior and condom use among men and women in Kinshasa, Zaire. Am J Public Health 81: 53-58, 1991.
11 - DARROW WW. Attitudes toward use and the acceptance of veneral disease prophylactics. In: CENTERS FOR DISEASE CONTROL. The condom: increasing utilization in the United States. U.S. Departament of Health, Education and Welfare. Public Health Service, Atlanta, p.173-185, 1974.

12 - HART G. Factors influencing veneral infection in a war environment. Br J Vener Dis 50: 68-72, 1974.

13 - HINGSON RW et al. Beliefs about AIDS, use of alcohol and drugs, and improtected sex among Massachusetts adolescents. Am J Public Health 80: 295-299, 1990.

14 - HART G. Role of preventive methods in the control of venereal disease. Clin Obstet Gynecol 8: 243-253, 1975.

15 - LIBBUS K. Women"s beliefs concerning condom acquisition and use. Public Health Nurs 12: 341-347, 1995.

16 - KATZNELSON S \& DREW WL. Efficacy of the condom as a barrier to the transmission of cytomegalovirus. J Infect Dis150: 155-157, 1984.

17 - VOELLER B \& POTTS M. Has the condom any proved value in preventing the transmission of sexual transmitted viral disease-for example, acquired immune deficiency syndrome? B M J 291: 1196, 1985.

18 - CONANT M et al. Condoms prevent transmission of AIDS - associated retrovirus. JAMA 255:1706, 1986.

19 - STONE KM; GRIMES DA \& MAGDER LS. Personal protection against sexually transmitted diseases. Am J Obste. Gynecol 155: 180-188, 1986.

20 - VAN DE PERRE P; JACOBS D \& SPRECHER-GOLDBERGER $S$. The latex condom, an efficient barrier against sexual transmission of AIDS-related virus. AIDS 1: 49, 1987.

21 - SOLOMON MZ \& DE JONG W. Preventing AIDS and other STDs through condom promotion: a patient education intervention. Am J Public Health 79: 453-458, 1989.

22 - PERLMAN JA et al. HIV risk difference between condom users and nonusers among U. S. heterosexual women. J AIDS 3: 155-165, 1990. 